\title{
Unemployment and psychological distress one year after childbirth in France
}

\author{
Marie-Josèphe Saurel-Cubizolles, Patrizia Romito, Pierre-Yves Ancel, Nathalie Lelong
}

\begin{abstract}
Study objective-To analyse the relation between unemployment and the psychological distress of mothers one year after childbirth.

Design-Multicentric survey concerning births occurring between September 1993 and July 1994.

Setting-In France: two maternity units in the Parisian area and one in ChampagneArdennes, in the east of France, comprising both urban and rural areas.

Participants-Primipara and secondipara women were interviewed three times: at birth by a face to face interview, five months and 12 months after the birth, by postal questionnaires, with a $83 \%$ response rate for the two postal questionnaires. The analysis includes 632 women who answered all three stages of the survey.
\end{abstract}

Measurements-Psychological distress was mainly assessed one year after birth by the 12-item General Health Questionnaire.

Results-After adjustment for unwanted pregnancy, marital conflicts, marital status, hospitalisation of the baby during the last year, lack of confiding relationship, depressive or anxious troubles before pregnancy, age, educational level and parity, unemployed women had an excess of psychological distress compared with employed women $(\mathrm{OR}=1.87 ; 95 \% \mathrm{CI}=1.12$, 3.13). The ratios for housewives were very close to those of employed women. Among the unemployed women, $60 \%$ had recently been without a job, since a few months before or after the birth. An excess of psychological distress among unemployed compared with employed women was observed in all social groups defined by the current or last occupation, but with various extents. Psychological distress was specially linked to the employment status in the group of women with the more qualified occupations.

Conclusion-Even after a birth, when women are very much involved in their maternal role, those seeking a job have worse mental health than those in a stable situation, either employed or housewives. In France, the unemployment rate among young women is high. It is specially important that social regulations protecting employment during and after pregnancy are adequately applied. Employers, legislators, such as medical doctors, have to be aware to this situation.

(F Epidemiol Community Health 2000;54:185-191)
The unemployment rate in France is high, particularly among women. In 1995, 10\% of the active male population and $14 \%$ of the active female population was unemployed, reporting to be seeking a job. ${ }^{1}$ Unemployment more frequently affects young adults: $18 \%$ of $25-29$ year old active women are unemployed. Unemployment increased during the past two decades: from national surveys of births, its rate was $5 \%$ in 1981 and $14 \%$ in $1995^{2}$ among pregnant active women.

There have been many studies investigating the link between unemployment and health, both physical and mental, using mortality or morbidity data. ${ }^{3-9}$ Most studies have shown a positive association between unemployment and illness. The classic debate concerns the direction of causality: does unemployment cause ill health or does ill health make unemployment more likely ? $^{10}{ }^{11}$ Longitudinal surveys, although unable to alleviate all the pitfalls, have indicated that both directions apply.

Most studies have focused on the male population despite the higher frequency of unemployment among women. Studies including women have tended to focus on the possible difference of the effects of unemployment between women and men. It has been suggested that unemployment is less detrimental for women than for men. ${ }^{6}{ }^{12}$ This difference may be attributable to gender roles. Women frequently have multiple roles as wife, mother and paid worker; without a job they may develop other functions; it is socially more acceptable for women to be unemployed than for men. It has been argued that, in specific contexts of high unemployment, women may use this opportunity to plan a pregnancy. ${ }^{13}$ Nevertheless, other studies have shown that the health effects of unemployment are similar for women and men..$^{14} 15$

This study focused on the contribution of unemployment to the psychological distress of new mothers. This relation may be specific for various reasons. The frequency of both psychological distress and unemployment is higher at this time. The months after childbirth are considered as a period of vulnerability for women's mental health. ${ }^{16-18}$ Stressful life events, lack of social support, marital conflicts and previous psychiatric or psychological problems are significant predictors of depression in the first few months after childbirth. The rate of unemployment may be high because pregnancy affects young women, who are particularly prone to unemployment and the very event of pregnancy and birth may result in the loss of a job. ${ }^{19}$ On the one hand, unemployment may be particularly detrimental to the mental health 
after childbirth because of financial worries and anxiety for the future related to the baby. On the other hand, there is probably no other point in the life of a woman when the pressure to take on a maternal role and duties is so great that such a low priority is given to employment. This should lessen the negative impact of unemployment on mental health.

The aim of this study was to analyse the relation between unemployment-defined as looking for a job whatever the employment status during pregnancy was-and the psychological distress of mothers one year after childbirth in France.

\section{Method}

SURVEY DESIGN

The survey included three maternity units that recruited women with various social characteristics: two units in the Parisian area and one in Champagne-Ardennes, comprising both urban and rural areas. Only primipara and secondipara women were included in the survey. Women with multiple pregnancies, a stillbirth or whose baby died before the interview were excluded. From September 1993 to July 1994, eligible women were contacted in the unit two or three days after delivery and were invited to participate: 761 of 770 accepted and completed a questionnaire with a face to face interview. Five and 12 months after the birth they received a postal questionnaire. The response rate for the two postal questionnaires was $83 \%$. Non-responders had a lower educational level; they were more likely to live without a partner and to report serious financial problems than responders. They were no differences related to women's health, the pregnancy or the newborn. ${ }^{20}$ This analysis concerns the 632 women who answered all three stages of the survey.

INDICATORS USED IN THE ANALYSIS

Outcome: psychological distress one year after

birth

It was assessed by:

1 The 12-item General Health Questionnaire (GHQ). ${ }^{21}$ This scale covers anxiety, depression and self esteem. Responses gave a total score between 0 and 12 . We analysed this scale using a cut off point between 2 and 3, as usual. Women with a score higher than 2 were considered to be suffering from psychological distress. We also considered women with scores higher than 5 corresponding to the 90th percentile of our sample.

2 The following questions related to the last month: "have you had feelings of depression or sadness? none/moderate/serious"; "have you had feelings of anxiety or tension? none/ moderate/serious"; "have you used psychotropic drugs? no/occasionally/regularly", the last two answers were collapsed; and "Since you came back from the maternity unit, how has your mental health been? good/fairly good/ bad".
Explanatory factor under investigation: employment status 12 months after the birth

It was described by three classes as follows: the unemployed, who were defined as women without a job who were seeking employment; the employed and housewives. The housewife group included a small number of students $(n=12)$.

\section{Possible confounders}

Social and demographical characteristics were used in the analysis: women's age at childbirth, birth order, educational level and women's current or last occupation, codified using the French national classification of occupations, ${ }^{22}$ collected by the first questionnaire; marital status and partner's employment status collected by the third questionnaire.

In a list of questions about life events during the 12 months after the birth, we asked the women whether they had experienced "serious financial problems" or "serious housing problems" in two distinct yes/no questions. Other three yes/no questions investigated marital conflicts: the first was about "frequent arguments", the second about "separation or serious threats of separation", and the third about "violence from the partner". The indicator used in this analysis was a positive answer to at least one of these three questions.

We considered if this pregnancy was wanted. Women were asked at the birth: "For this pregnancy, would you say that-you wanted it at this time/you wanted a child but not at this time/you did not want this pregnancy". The last two answers were combined and classified as women who did not want this pregnancy. Women were classed as having a confiding relationship if they declared that they could confide in one of their friends or relations in case of worries 12 months after the birth.

Two indicators were used to describe the baby's health status: one at birth was the admission to a neonatal intensive care unit (NICU) and the other, dealt with the third questionnaire, was the hospital admission of the child during the first year of life.

At childbirth, we assessed the women's previous mental health status asking: "Before the pregnancy, did you have depressive or anxious feelings? no/occasionally/frequently".

STATISTICAL ANALYSIS

We described the employment status, the previous job experience of unemployed women, if any. We analysed the links between employment status and the various psychological distress indicators. Then we studied the links between the possible confounders, described above, and the employment status on the one hand and the psychological distress, measured by the GHQ, on the other hand. This last step of the analysis is not reported in this paper. We used the $\chi^{2}$ test for these comparisons.

The relation between psychological distress and employment status was assessed by logistic regression including all the factors that were significantly related to employment status or health outcome in this sample. A similar 
Table 1 Psychological distress 12 months after the birth according to employment status

\begin{tabular}{|c|c|c|c|c|}
\hline & $\begin{array}{l}\text { Unemployed } \\
\text { women }(n=94)\end{array}$ & $\begin{array}{l}\text { Employed women } \\
(n=426)\end{array}$ & $\begin{array}{l}\text { Houserwives } \\
(n=112)\end{array}$ & \\
\hline \multicolumn{5}{|l|}{ 12-item GHQ score ${ }^{\star}$} \\
\hline $0-2$ & 51.1 & 69.5 & 64.3 & \\
\hline $3-5$ & 28.7 & 21.1 & 25.0 & $\mathrm{p}<0.006$ \\
\hline more than 5 & 20.2 & 9.4 & 10.7 & \\
\hline \multicolumn{5}{|c|}{ Feelings of depression or sadness ${ }^{\star}$} \\
\hline no & 48.9 & 69.0 & 68.2 & \\
\hline moderate & 40.4 & 23.2 & 22.7 & $\mathrm{p}<0.005$ \\
\hline serious & 10.6 & 7.8 & 9.1 & \\
\hline \multicolumn{5}{|c|}{ Feelings of anxiety or tension ${ }^{\star}$} \\
\hline no & 38.3 & 45.3 & 50.0 & \\
\hline moderate & 46.8 & 41.5 & 34.6 & NS \\
\hline serious & 14.9 & 13.2 & 15.4 & \\
\hline Psychotropic drug use & 16.0 & 10.4 & 10.0 & NS \\
\hline \multicolumn{5}{|c|}{ Self reported mental health over the past year } \\
\hline good & 41.9 & 53.9 & 52.2 & \\
\hline fairly good & 46.2 & 39.5 & 41.4 & $\mathrm{p}<0.05$ \\
\hline bad & 11.8 & 6.6 & 6.3 & \\
\hline
\end{tabular}

^During the past month. Data shown as percentages.

analysis was also performed after stratification for three main occupational groups. The variables were included in the models as they are described in the tables 2 and 3, except for marital status and conflicts: we computerised a three classes variable: couple without conflicts, couple with conflicts, lone mother.

Lastly, we investigated the psychological distress according to the duration of unemployment.

Statistical analyses were done using SAS and BMDP software.

\section{Results}

One year after childbirth, 94 women, $15 \%$ of the sample, reported that they were looking for a job; $65 \%$ had a job and the remaining $20 \%$ were housewives.

\section{PREVIOUS JOB EXPERIENCE OF UNEMPLOYED}

WOMEN

More than half of the women looking for a job had been employed recently: 38\% (36 women) had returned to work after childbirth and had lost their job (voluntary or unfair dismissal) and $22 \%$ (21 women) had a job during the

Table 2 Demographic and social characteristics of the women by employment status 12 months after the birth

\begin{tabular}{|c|c|c|c|c|}
\hline & $\begin{array}{l}\text { Unemployed } \\
\text { women }(n=94)\end{array}$ & $\begin{array}{l}\text { Employed } \\
\text { women }(n=426)\end{array}$ & $\begin{array}{l}\text { Housewives } \\
(n=112)\end{array}$ & \\
\hline \multicolumn{5}{|l|}{ Age at delivery (y) } \\
\hline under 25 & 39.4 & 18.5 & 26.8 & \multirow{4}{*}{$\mathrm{p}<0.001$} \\
\hline $25-29$ & 36.2 & 51.4 & 43.8 & \\
\hline $30-34$ & 21.3 & 24.6 & 17.9 & \\
\hline 35 or over & 3.2 & 5.4 & 11.6 & \\
\hline \multicolumn{5}{|l|}{ Educational level } \\
\hline low & 29.8 & 14.6 & 31.2 & \multirow{3}{*}{$\mathrm{p}<0.001$} \\
\hline intermediate & 42.6 & 36.2 & 39.3 & \\
\hline high & 27.7 & 49.3 & 29.5 & \\
\hline \multicolumn{5}{|l|}{ Parity } \\
\hline first child & 57.4 & 56.3 & 41.1 & \multirow[b]{2}{*}{$\mathrm{p}<0.02$} \\
\hline second child & 42.6 & 43.7 & 58.9 & \\
\hline \multicolumn{5}{|l|}{ Marital status ${ }^{\star}$} \\
\hline married & 54.3 & 63.6 & 76.4 & \multirow{3}{*}{$\mathrm{p}<0.01$} \\
\hline cohabiting & 38.3 & 33.1 & 19.1 & \\
\hline lone mother & 7.4 & 3.3 & 4.6 & \\
\hline Partner unemployed ${ }^{\star} \dagger$ & 9.2 & 5.4 & 7.8 & NS \\
\hline \multicolumn{5}{|c|}{ Current or last women' occupation } \\
\hline professional & 2.1 & 17.8 & 5.4 & \multirow{6}{*}{$\mathrm{p}<0.001$} \\
\hline intermediate & 17.0 & 29.6 & 17.0 & \\
\hline clerk & 29.8 & 30.8 & 25.0 & \\
\hline service worker & 31.9 & 13.8 & 29.5 & \\
\hline manual worker & 9.6 & 6.1 & 6.2 & \\
\hline other or non-specified & 9.6 & 1.9 & 17.0 & \\
\hline
\end{tabular}

${ }^{\star}$ Data collected 12 months after birth. †Only for married or cohabiting women. Data shown as percentages. pregnancy. The other women did not have recent job experience: $27 \%$ (25 women) reported they were looking for a job during the pregnancy and 13\% (12 women) were not employed during the pregnancy and did not look for a job. Overall only $7 \%$ of these 94 women had never been employed.

EMPLOYMENT STATUS AND PSYCHOLOGICAL DISTRESS: BIVARIATE ANALYSES (TABLE 1) The percentage of psychological distressGHQ score higher than 2-was significantly higher among unemployed women $(48.9 \%)$ than among the employed (30.5\%) and housewives $(35.7 \%)(p<0.001)$. The prevalence of severe psychological distress-GHQ score over 5-was also higher among unemployed women than among the other two groups. Feelings of depression or sadness were more frequent among unemployed mothers; psychotropic drug use and feelings of anxiety were not significantly related to employment status despite the same trend. Overall, unemployed women reported poorer mental health during the past year than did the other women.

\section{EMPLOYMENT STATUS ACCORDING TO SOCIAL}

AND DEMOGRAPHIC CHARACTERISTICS (TABLE 2) Age, educational level, parity, and marital status distributions were significantly different depending on the employment status 12 months after delivery. Unemployed women were more often young women, under 25 , with a low educational level, lone mother and with a first baby. The percentage of women with an unemployed partner was not significantly different in the three groups. Strong differences were observed in current or last occupations of women: unemployed women had less frequently the more skilled occupationsprofessionals or intermediate- and were more often service workers. Nevertheless, depending on the factors, the unemployed women differed from the employed women or from the housewives.

As expected, serious financial problems were more frequent among unemployed than among the other women, $47 \%$ compared with $19 \%$ $(\mathrm{p}<0.001)$; serious housing problems (for example, threats of eviction, very poor conditions) were also more frequent among unemployed women, $8 \%$ compared with $3 \%$ $(\mathrm{p}<0.05)$.

EMPLOYMENT STATUS ACCORDING TO HEALTH, PREGNANCY AND COUPLE CHARACTERISTICS (TABLE 3)

Women who were unemployed 12 months after the birth were not more likely than other women to have reported feelings of anxiety or depression before the index pregnancy. The proportion of unwanted pregnancies was higher among unemployed and housewives than among employed women. The percentage of women whose child was admitted to hospital during the year was much higher among women looking for a job than among other women whereas there was no difference in the rate of admission to neonatal unit after the delivery, which was used as an indicator of the 
Table 3 Characteristics of the woman's or the child's health, the pregnancy and the couple by employment status 12 months after the birth

\begin{tabular}{|c|c|c|c|c|}
\hline & $\begin{array}{l}\text { Unemployed } \\
\text { women } \\
(n=94)\end{array}$ & $\begin{array}{l}\text { Employed } \\
\text { women } \\
(n=426)\end{array}$ & $\begin{array}{l}\text { Housewives } \\
(n=112)\end{array}$ & \\
\hline \multicolumn{5}{|l|}{ Depressive or anxious feelings before the pregnancy* } \\
\hline no & 52.1 & 51.2 & 52.2 & \\
\hline occasional & 22.3 & 23.5 & 18.9 & NS \\
\hline frequent & 25.5 & 25.4 & 28.8 & \\
\hline Unwanted pregnancy* & 20.2 & 11.0 & 21.4 & $\mathrm{p}<0.004$ \\
\hline Hospitalisation of the newborn in a NICU at birth ${ }^{\star}$ & 8.5 & 7.5 & 9.0 & NS \\
\hline Baby hospitalised during the first year $\dagger$ & 27.7 & 12.5 & 18.2 & $\mathrm{p}<0.001$ \\
\hline Marital conflicts $\dagger$ & 26.7 & 18.0 & 20.0 & NS \\
\hline Lack of confiding relationship & 25.8 & 20.4 & 19.6 & NS \\
\hline
\end{tabular}

NICU : neonatal intensive care unit. ${ }^{\star}$ Data collected at birth. $\dagger$ Data collected 12 months after birth. Data shown as percentages.

Table 4 Odds ratios (OR) for psychological distress, defined by $G H Q-12>2$ and $G H Q-12>5$, according to employment status 12 months after the birth

\begin{tabular}{lll}
\hline & Crude OR (95\%CI) & Adj ${ }^{\star}$ OR (95\%CI) \\
\hline & GHQ $>2$ & GHQ $>2$ \\
Unemployed women & $2.17(1.37,3.43)$ & $1.87(1.12,3.13)$ \\
Employed women & 1 & 1 \\
Housewives & $1.28(0.83,1.99)$ & $1.11(0.67,1.84)$ \\
& $\mathrm{p}<0.004$ & $\mathrm{p}<0.06$ \\
Unemployed women & GHQ $>5$ & $\mathrm{GHQ}>5$ \\
Employed women & $1.46(1.35,4.50)$ & $2.19(1.10,4.36)$ \\
Housewives & $1.15(0.58,2.28)$ & 1 \\
& $\mathrm{p}<0.02$ & $\mathrm{p}<0.09(0.49,2.33)$ \\
Number & 629 & 613 \\
\hline
\end{tabular}

*Adjusted by logistic regression for unwanted pregnancy, marital conflict, cohabiting status, hospitalisation of the baby during the last year, lack of confiding relationship, mental health status before pregnancy, age, educational level and parity of the woman.

baby's health status at birth. Slightly more unemployed women than employed women and housewives reported marital conflicts; the same trend was observed for the lack of a confidante but these last two differences were not significant.

EMPLOYMENT STATUS AND PSYCHOLOGICAL DISTRESS: MULTIVARIATE ANALYSES Unadjusted odds ratios of GHQ $>2$ and of GHQ $>5$ were significantly higher than 1 for unemployed women compared with employed women (table 4). After adjustment for marital conflicts, cohabiting situation, unwanted pregnancy, hospitalisation of the baby, mental

Table 5 Percentages and odds ratios for positive GHQ according to employment status depending on the current or last occupation

\begin{tabular}{|c|c|c|c|c|}
\hline & \multirow[b]{2}{*}{ (n) } & \multicolumn{2}{|c|}{$G H Q>2$} & \multirow{2}{*}{$\begin{array}{l}G H Q>5^{\star} \\
\%\end{array}$} \\
\hline & & $\%$ & $\operatorname{adjt}$ OR $(95 \% C I)$ & \\
\hline \multicolumn{5}{|c|}{ Professionals or intermediate occupations } \\
\hline Unemployed women & $(18)$ & 55.6 & $4.65(1.55,13.9)$ & 22.2 \\
\hline Employed women & (201) & 27.4 & 1 & 7.5 \\
\hline Housewives & $(25)$ & 56.0 & $\begin{array}{l}3.24(1.22,8.62) \\
\mathrm{p}<0.003\end{array}$ & $\begin{array}{l}12.0 \\
\mathrm{p}<0.10\end{array}$ \\
\hline \multicolumn{5}{|l|}{ Clerks } \\
\hline Unemployed women & (28) & 50.0 & $1.56(0.58,4.18)$ & 14.3 \\
\hline Employed women & (130) & 35.4 & 1 & 9.2 \\
\hline Housewives & $(28)$ & 25.0 & $\begin{array}{l}0.48(0.16,1.45) \\
\text { NS }\end{array}$ & $\begin{array}{l}10.7 \\
\text { NS }\end{array}$ \\
\hline \multicolumn{5}{|c|}{ Manual or service workers $\ddagger$} \\
\hline Unemployed women & $(47)$ & 44.7 & $1.41(0.59,3.38)$ & 23.4 \\
\hline Employed women & (93) & 29.0 & 1 & 14.0 \\
\hline Housewives & (59) & 32.2 & $\begin{array}{l}1.00(0.41,2.42) \\
\text { NS }\end{array}$ & $\begin{array}{l}10.2 \\
\text { NS }\end{array}$ \\
\hline
\end{tabular}

${ }^{\star}$ Multivariate analyses could not be performed because of small numbers. †Adjusted for unwanted pregnancy, marital conflict, cohabiting status, hospitalisation of the baby during the last year, lack of confiding relationship, mental health status before pregnancy, age, educational level and parity of the woman. ¥Including other and unspecified occupations.

\section{KEY POINTS}

- Women who were looking for a job were more often distressed one year after childbirth than employed or housewives.

- The detrimental effect of unemployment on psychological well being seems to be larger among the more qualified women.

- More than half of unemployed women had lost their job since a few months before or after the birth.

- The unemployed women's children were more frequently hospitalised during the first year despite similar health status at birth.

distress before pregnancy, women's age, educational level and parity, these odds ratios remained significantly higher than 1 . The adjusted odds ratios were slightly lower than the crude ratios, showing a moderate confounding effect of the various factors included in the multivariate analyses. The risk for housewives was very similar to that for employed women.

Unemployed women were more likely than other women to be distressed whatever their current or last occupation (table 5). The link between psychological distress and employment status was specially strong for professional or intermediate occupations. For these occupations, the frequency of women with the GHQ score higher than 2 was similar for housewives and unemployed women whereas the frequency of GHQ higher than 5 was lower for housewives than for unemployed. Among clerks, manual and service workers, housewives were less distressed than unemployed women, using both thresholds of the GHQ score. These differences were not significant however, because of the small sample sizes. The percentage of women with GHQ higher than 5 was lowest for employed women in professional or intermediate occupations and highest for unemployed women who had previously worked as manual or service workers.

Besides, the hospitalisation of the child in the first year was more likely among unemployed compared with employed women: OR $=2.55$ (95\% CI 1.42, 4.58), after adjustment for all factors included in the multivariate analysis, such as described on table 4 , and for maternal psychological distress. The odds ratio for housewives was not significantly different from $1:$ OR $=1.64(95 \%$ CI $0.89,3.01)$. Globally the employment status of the mother was significantly associated with the hospitalisation of the child in the first year $(\mathrm{p}<0.007)$.

\section{DURATION OF UNEMPLOYMENT AND}

PSYCHOLOGICAL DISTRESS

The proportion of women with GHQ higher than 2 was $49 \%$ among those who had recently lost their job-during pregnancy or after the birth (57 women were in this situation) - and was $47 \%$ among those who were unemployed before the pregnancy ( 37 women). The percentages of women with a GHQ score higher 
than 5 were $19 \%$ and $22 \%$ respectively. These differences were not significant.

\section{Discussion}

This study shows that unemployed women were more often distressed one year after a first or a second birth than employed women or housewives. Most of the unemployed had been without a job since a few months before or after the birth. As for the unemployed population in general, women unemployed after childbirth were more disadvantaged socially than other women, with low educational levels, a previous unskilled occupation and lone motherhood. Their babies were more frequently hospitalised during the first year of life. However, these characteristics together cannot totally account for the excess of psychological distress among these women.

This study has several limitations and strengths. Firstly, the sample is not representative at the national level. However, compared with a 1995 national sample of births, ${ }^{2}$ age, educational level and marital status were similar for first time and second time mothers. Our sample included more women who had worked during pregnancy, probably because of the mainly urban recruitment. No national estimate of the rate of unemployment or of return to work in the first year after childbirth is available in France. Secondly, this sample was restricted to primipara and secondipara women. From the same national birth data, it has been estimated that first and second children account for $76 \%$ of all births. We assumed that the number of children she has is an important element in a woman's decisions regarding employment and we wanted to limit the variability in the sample so we did not include all multipara women. Moreover, the length of maternity leave in France is different for first time and second time mothers and those of more than two children: this could create confusion about the moment at which they reported to look for a job.

This survey had a design involving three contacts with the women. This approach made it possible to obtain prospective data about job history and some of the factors included in the analysis such as the wantedness of the pregnancy, the admission of the baby to a neonatal intensive care unit or the woman's previous psychological health status, which were collected at birth with no knowledge of the job nor mental health status one year later. However, the main disadvantage of a longitudinal design is that subjects are lost: because of the social characteristics of the non-responders, we probably lost more often women who were unemployed or housewives one year after childbirth, whereas there was no evidence that the selection was different according to the health status of the women. ${ }^{20}$ Nevertheless, the response rate was high and this may have left only a very small margin for such a bias.

Psychological distress was assessed by various indicators and the results were consistent. In the analysis, we used mainly the GHQ-12 score, which has been used in many studies on general populations, ${ }^{23}{ }^{24}$ women after childbirth $^{25}$ and particularly to study the health status of the unemployed. ${ }^{26}{ }^{27} \mathrm{~A}$ French version of the GHQ has been validated in 28 items, showing high sensibility and specificity in reference to DSM III-R diagnoses, ${ }^{28}$ no validation in French langage is available in 12 items. Nevertheless, it has been used in several studies. ${ }^{29}$ The usual threshold is $2 / 3$ and we performed our analysis with this cut off point. We observed a high prevalence of distressed women, $33.9 \%$ (95\% CI:30.2, 37.6) for the whole sample, higher than that reported in a general population, including men and women, in Great Britain in $1991(24.6 \%),{ }^{23}$ and close to the rate reported in Amsterdam in 1992-93 $(33 \%) .^{24}$ The frequency of minor psychiatric disorders, particularly depressive symptoms, is generally higher among women than among men. ${ }^{30}{ }^{31}$ In Finland, in 1993, 24\% of married women were found to have a GHQ-12 higher than $2 .{ }^{27}$ Another survey in Finland in 1992 showed that $28 \%$ of women were distressedassessed by the same method- 1 to 2 months after delivery and $19.4 \%$ two years later. ${ }^{32}$ Because of this high frequency, we performed the same analysis using a higher cut off point. It has also been suggested that such a scale differentially assesses mental disorders depending on the culture of the population investigated. The threshold for GHQ-12 seems to be higher for Latin than for Anglo-Saxon populations. ${ }^{33}$ So, it may be important to check the validity of the associations with employment status at various scores for this scale. Using a cut off point of 5/6 yields an overall prevalence of $11.3 \%$ (95\% CI: 8.8, 13.8), probably similar to that observed among men and women in Amsterdam, where the rate was $13.8 \%$ with a cut off point at $4 / 5 .{ }^{24}$ With this definition at $5 / 6$, we estimated a frequency close to that obtained for an Italian sample of recent mothers collected using the same design, 9.1\% (95\% CI: 7.0, 11.2) 12 months after childbirth. ${ }^{33 a}$

Regardless of the cut off point, unemployed women were more often distressed than other women, as reported in several other studies. ${ }^{4} 273435$ The statistical associations were very similar with both definitions, with odds ratios of about 2 . The results with the GHQ were consistent with those obtained by the other indicators of mental health we included in our survey, the association being stronger with self reports of depressive feelings than with self reports of anxiety, as was also noted by Dew et al. ${ }^{34}$ Even after a birth, when women are very much involved in their maternal role, those seeking a job have worse mental health than those in a stable situation, either employed or housewives. Most unemployed had recently lost their job; for some, the loss of the job was probably because of the birth, with employers trying to avoid the complications of maternity leave or the lower availability of women with young children. We have previously shown that despite protective legal measures, unfair dismissals occurred at the time of pregnancy. ${ }^{19}$

The duration of unemployment might have differential impact from two phenomena: on 
the one hand, recent unemployment may be more strongly associated with distress because it may be more unexpected for women who had planned the birth before becoming unemployed, making it more stressing to cope with recent constraints. On the other hand, long term unemployment may be very discouraging, leaving little hope of finding a job and resulting in more difficult living conditions over a long period. We found no significant differences according to the duration of unemployment.

It is difficult to determine the direction of the statistical association between unemployment and health ${ }^{9} 10$ and several studies have shown a selection effect by health. ${ }^{1136}$ People with poorer health have a higher risk of losing their job and a lower chance of re-employment. ${ }^{7}$ Nevertheless, several studies have shown that such a selection cannot account for the excess of mental health disorders among the unemployed. ${ }^{34}$ Our prospective study showed that, at the time of the birth, women described their previous mental health status in the same way, regardless of their employment status one year later. Thus, the difference between the groups probably arose during the 12 months after the birth.

Unemployment may affect mental health via various mechanisms. Firstly, unemployment often results in financial strain; almost half the unemployed women reported serious money problems. The lack of money leads to several kinds of deprivation, difficult living conditions or poor housing. The impact of poverty on mental health is well documented in the general population, ${ }^{23} 3738$ and for mothers of young children. ${ }^{17}{ }^{39}$ The effects of poverty are consistent with the high rate of severe psychological distress we observed for the unemployed in the group including manual, service workers and women with unspecified occupation, probably the poorest women in the sample. Secondly, unemployment may damage self esteem. ${ }^{40}$ Not having a job may be interpreted as not being able to live autonomously. If occupation is an important component of identity, then unemployment may directly threaten this identity. Moreover the status of "unemployed" has low social prestige whereas in France nowadays the socially approved role is to be an employed mother, even with very young children. We found that $83 \%$ of women employed during pregnancy returned to work before the first birthday of the child, this rate was much higher among the more qualified women, most of whom had returned to work within the first four months after the birth. ${ }^{41}$ This may explain why the link between unemployment and psychological distress is strongest among the most highly qualified women: they made a great investment in schooling and occupational background and failed to translate this into a career. Nevertheless it is not possible to distinguish precisely the two "mechanisms": whatever their social class, the unemployed may have financial strains and feelings of failure.

In addition to these direct effects of unemployment on mental health our results suggest other possible indirect pathways. Hospitalisa- tion of the baby during the first year was much more frequent among unemployed women. Several explanations for this are possible. Firstly, the poor living conditions of the family may have detrimental effects on the baby's health. Secondly, it is possible that unemployed mothers choose different health care providers for their babies: having little money or being only partially covered by health insurance, they may be more likely to bring their child to the emergency department of the hospital. Thirdly, it is possible that, for a small number of women, the bad health status of the baby led to the loss of the job, with too much leave taken because of the baby's sickness. Lastly, medical professionals in hospitals may have been more ready to admit the baby to hospital if the mother was socially deprived, to improve the baby's chances of recovery. The same may also be true if the mother was depressed, whatever the social situation. We could not test which of these explanations applied because detailed data for each event were not available. We observed only that the medical reasons for the hospitalisation of the babies were similar for unemployed and other women, the severity of the disease was not recorded. As it was difficult to be sure that the babies were hospitalised because of the effects of unemployment, we adjusted for this factor, as a confounding factor, conceding the risk to over adjust the association between unemployment and psychological distress.

Unemployment is an individual situation as is its cohort of worries, but it is also a social problem resulting from the economic functioning of the societies. Social and economic difficulties may have an impact on the health of people. Our results illustrate the impact of unemployment on a specific population, women with one year old children, in France.

We are gratefully indebted to all women who participated to this survey. We thank the medical managers of the three maternity units who allowed the survey to take place in their departments. We would also like to thank the three interviewers, Catherine Salobir, Corinne Rodella and Véronique Chesnoy, thanks to whom we obtained a particularly high response rate.

Funding: the survey was funded by a CNAMTS-INSERM

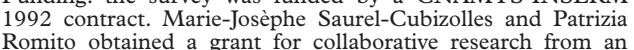
INSERM-CNR agreement (1997-1998). Conflicts of interest: none.

1 Insee. Enquête sur l'emploi de 1995. Résultats détaillés. Paris: Insee Résultats, Emploi-Revenus 1996; no 101-102.

2 Blondel B, Bréart G, du Mazaubrun C, et al. La situation périnatale en France. Evolution entre 1981 et 1995. f perinatal en France. Evolution entre 1981

3 Brenner MH, Mooney A. Unemployment and health in the context of economic change. Soc Sci Med 1983;17:1125context of economic change. Soc Sci Med 1983;17:1125 38

4 Ezzy D. Unemployment and mental health: a critical review. Soc Sci Med 1993;37:41-52.

5 Benavides FG, Garcia AM, Saez-Lloret I, et al. Unemployment and health in Spain. Eur F Public Health 1994;4:1037.

6 Lahelma E. Unemployment and mental well-being: elaboration of the relationship. Int $\mathcal{f}$ Health Services 1992;22:26174.

7 Claussen B, Bjorndal A, Hjort PF. Health and reemployment in a two year follow up of long term unemployed. $\mathcal{F}$ Epidemiol Community Health 1993;47:1418.

8 Lewis G, Sloggett A. Suicide, deprivation and unemployment : record linkage study. $B M \mathcal{F} 1998 ; 317: 1283-6$.

9 Janlert U. Unemployment as a disease and diseases of the Janlert U. Unemployment as a disease and diseases of the
unemployed. Scand f Work Environ Health 1997;23 (suppl 3):79-83.

10 Bartley $M$. Unemployment and health: selection or causation-a false antithesis? Sociology Health Illness 1988; 10:41-67. 
11 Arrow JO. Estimating the influence of health as a risk factor of unemployment: a survival analysis of employment durations for workers surveyed in the German Socio-E

12 Platt S, Micciolo R, Tansella M. Suicide and unemployment in Italy:description, analysis and interpretation of recent trends. Soc Sci Med 1992;34:1191-201.

13 Bungener M, Horellou-Lafargue C, Louis MV. Chômage et santé. Paris: Economica, 1982:158.

14 Leeflang RLI, Klein-Hesselink DJ, Spruit IP. Health effects of unemployment - II. Men and women. Soc Sci Med 1992; 34:351-63.

15 Ensminger ME, Celentano DD. Gender differences in the effect of unemployment on psychological distress. $S o c S_{c i}$ Med 1990;30:469-77.

16 Romito P. Postpartum depression and the experience of motherhood. Acta Obstet Gynecol Scand 1990, 69 (suppl 154):5-37.

17 O'Hara M. Swain A. Rates and risk of post-partum depression-a meta-analysis. Int Review Psychiatry 1996;8: depression $37-54$.

18 Kumar R. Postnatal mental illness : a transcultural perspective. Soc Psychiatry Psychiatr Epidemiol 1994;29:250-64.

19 Romito P, Saurel-Cubizolles MJ. Fair law, unfair practices ? Benefiting from protective legislation for pregnant worker in Italy and France. Soc Sci Med 1992;35:1485-95.

20 Lelong N, Saurel-Cubizolles MJ, Romito P. Réponses à une enquête postale sur la santé des femmes après une naissance: importance des relances et caracteristiques des non-répondantes. Rev Epidémiol Santé Publique 1997;45: 305-14.

21 Goldberg DP, Gater R, Sartorius N, et al. The validity of two version of the GHQ in the WHO study of mental illness in general health care. Psychol Med1997;27:191-7.

22 Insee. Nomenclature des professions et catégories socioprofessionnelles. Paris: Insee, 1983.

23 Weich S, Lewis G. Poverty, unemployment and common mental disorders: population based cohort study. $B M \mathcal{F}$ mental disorders:

24 Reijneveld SA, Schene AH. Higher prevalence of mental disorders in socioeconomically deprived urban areas in the Epidemiol Community Health 1998;52:2-7.

25 Viinamaki $H$, Rastas S, Tukeva L, et al. Postpartum mental health. $\mathcal{F}$ Psychosom Obstet Gynecol 1994;15:141-6.

26 Lahelma E. Unemployment and mental well-being: elaboration of the relationship. Int $\mathcal{F}$ Health Services 1992;22:261-74.
27 Viinamaki H, Kontula O, Niskanen L, et al. The association between economic and social factors and mental health in Finland. Acta Psychiatr Scand 1995;92:208-13.

28 De Mont-Marin F, Hardy P, Lépine JP, et al. Validation d'une version française du General Health Questionnaire GHQ-28) dans une population de diabétiques. L'Encéphale 1993;19:293-301.

29 Lépine JP. Questionnaire de santé GHQ. In: Guelfi JD. L'évaluation clinique standardisée en psychiatrie. Vol 1. Paris: Editions Médicales Pierre Fabre, 1993:149-57.

30 Nazroo JY, Edwards AC, Brown GW. Gender differences in the prevalence of depression: artefact, alternative disorders, biology or roles? Sociology Health Illness 1998;20:312-30.

31 Lovell A, Fuhrer R. Troubles de la santé mentale. In: MJ Saurel-Cubizolles, B Blondel, eds. La santé des femmes. Paris: Flammarion, 1996:252-83.

32 Viinamaki $\mathrm{H}$, Niskanen L, Pesonen P, et al. Evolution of postpartum mental health. I Psychosom Obstet Gynaecol 1997;18:213-19.

33 Lewis G, Araya RI. Is the General Health Questionnaire (12 item) a culturally biased measure of psychiatric disorder ? Soc Psychiatry Psychiatr Epidemiol 1995;30:20-5.

33a Romito P, Saurel-Cubizolles MJ, Lelong N. What makes new mothers unhappy: pychological distress one year after birth in Italy and France. Soc Sci Med 1999;49:1651-61.

34 Dew MA, Bromet EJ, Penkower L. Mental health effects of job loss in women. Psychol Med 1992;22:751-64.

35 Hammarström A. Health consequences of youth unemployment-Review from a gender perspective. Soc Sci Med 1994;38:699-709.

36 Montgomery SM, Bartley MJ, Cook DG, et al. Health and social precursors of unemployment in young men in Great Britain. F Epidemiol Community Health 1996;50:415-22.

37 Hopton JL, Hunt SM. Housing conditions and mental health in a disadvantaged area in Scotland. $f$ Epidemiol Community Health 1996;50:56-61.

38 Brown GW, Harris T. Social origins of depression. London: Tavistock, 1978

39 Brown GW, Moran PM. Single mothers, poverty and depression. Psychol Med 1997;27:21-33.

40 Turner JB. Economic context and the health effects of unemployment. F Health Soc Behavior 1995;36:213-29.

41 Saurel-Cubizolles MJ, Romito P, Escriba-Aguir V, et al. Returning to work after childbirth in France, Italy and Spain. European Sociological Review 1999;15:179-94. 